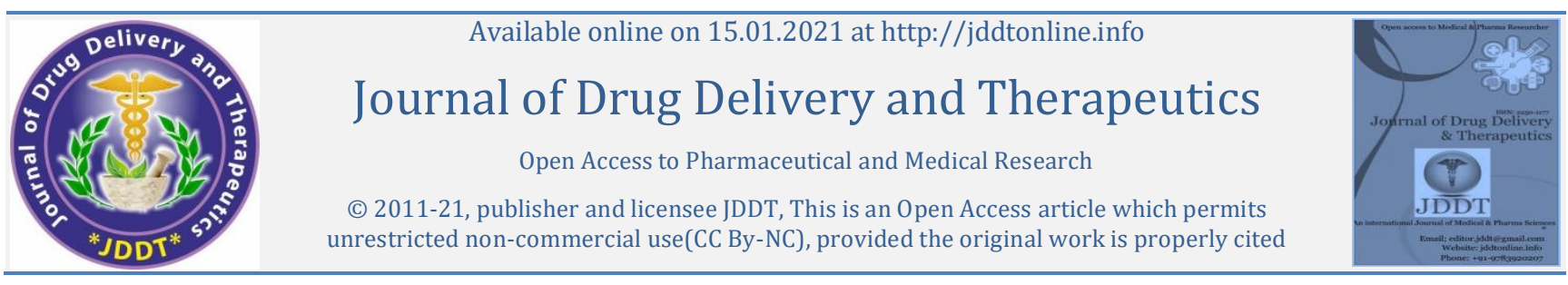

(C) 2011-21, publisher and licensee JDDT, This is an Open Access article which permits

Open Access Full Text Article

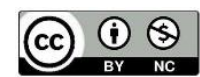

Research Article

\title{
Study on correlation of Antioxidant activities with presence of phenolic and Flavanoid contents in Emblica officinalis and Terminalia chebula
}

\author{
Ranjan Singh*, Suhas Kumar \\ Department of Microbiology, Faculty of Sciences, Dr. Ram Manohar Lohia Avadh University, Ayodhya, U.P., India
}

Article Info:

Article History:

Received 09 Nov 2020;

Review Completed 23 Dec 2020

Accepted 30 Dec 2020;

Available online 15 Jan 2021

Cite this article as:

Singh R, Kumar S, Study on correlation of Antioxidant activities with presence of phenolic and Flavanoid contents in Emblica officinalis and Terminalia chebula, Journal of Drug Delivery and Therapeutics. 2021; 11(1):32-35

DOI: http://dx.doi.org/10.22270/jddt.v11i1.4667

*Address for Correspondence:

Dr. Ranjan Singh, Associate Professor, Department of Microbiology, Faculty of Sciences, Dr. Ram Manohar Lohia Avadh University, Ayodhya, U.P.

\author{
Abstract
}

Background: Reactive oxygen species have been known to cause cellular damages that have been implicated to be a causal of major diseases; therefore natural antioxidants have shown a significant impact on human robustness. The present study was carried out to appraise the anti-oxidant activities (In- vitro) and their correlation with presence of Flavanoid and Phenolic content in fruits of Terminalia chebula and Emblica officinalis fruit extracts which is common in herbal Kitchen of India.

Methods: The 70\% extracts of fruits from Terminalia chebula and Emblica officialis were applied for the study of Anti-oxidant activity. Scavenging radical ability of extracts of these extracts were judged by radical like DPPH.

Results: The capability of the extracts of Fruits in exhibiting Antioxidative properties follow the sequence of Terminalia chebula $>$ Emblica officinalis. Since the antioxidant activities were studied in comparison with the standards of Flavanoid, Phenolic and Ascorbic acid. The Flavanoid and Phenolic quantity / amount along with subsequent dilution of Ascorbic acid as in case of DPPH radical assay were assessed as $127.60 \pm 0.001 \mathrm{mg} / \mathrm{ml}, 133.00 \pm 0.003 \mathrm{mg} / \mathrm{ml}$ for Phenolic Content as Gallic acid equivalent per $100 \mathrm{mg}$ of the Fruit extract.

Keywords: Antioxidant, Phenol, Flavanoid, Emblica, Terminalia.

\section{INTRODUCTION:}

Oxidative stress plays an important role in the pathogenesis of various diseases such as atherosclerosis, alcoholic liver cirrhosis and cancer etc. Oxidative stress is initiated by reactive oxygen species (ROS), such as superoxide anion $\left(\mathrm{O}^{-}\right.$ ${ }^{2}$ ), perhydroxy radical (HOO-) and hydroxyl radical (HO-). These radicals are formed by a one electron reduction process of molecular oxygen $\left(\mathrm{O}_{2}\right)$. ROS can easily initiate the lipid peroxidation of the membrane lipids, causing damage of the cell membrane of phospholipids, lipoprotein by propagating a chain reaction cycle 1,2 . Thus, antioxidants defense systems have coevolved with aerobic metabolism to counteract oxidative damage from ROS. Most living species have efficient defense systems to prevent themselves against oxidative stress induced by ROS ${ }^{3}$. Recent investigations have shown that the antioxidant properties of plants could be correlated with oxidative stress defense and different human diseases and aging process 4 . In this respect flavonoids and other polyphenolic compounds have received the greatest attention $18,19,20$.

The fruits of Terminalia chebula and Emblica officinalis are widely used in the Indian traditional system of medicine. The half ripe fruit of the pericarp of T. chebula fruit were reported to be purgative ${ }^{5}$. The fruit of $T$. chebula was traditionally used to cure asthma, urinary disorders, heart disease and it has cardiotonic activity6,7. In Ayurveda, the fruit of $E$. officinalis is used as a cardiotonic, cerebral and intestinal tonic8, and it is also reported to have anticancer properties $^{9}$. The fruit of E. officinalis is a rich source of vitamin $\mathrm{C}$, a well-known antioxidant ${ }^{10}$. The crude extract of E. officinalis was reported to counteract the hepatotoxic and renotoxic effects of metals ${ }^{11}$ due to antioxidant properties. Emblica officinalis popularly known as amla, is a deciduous tree having average height of 5.5 meters. The fruit is drupe, fleshy globose, $1.5-2.5 \mathrm{~cm}$. in diameter, smooth, shiny with light colored specks. It is distinctly marked in six lobes. The fruit is green when tender but the color changes to light yellow or brick red on maturity. The taste is sour and astringent giving feeling of sweetness afterwards ${ }^{5}$. The plant is found in the mixed deciduous forests of India, Sri Lanka, China, Bangladesh and Malaya ascending to 1,500 meters on the hills.

Dried fruit is useful in haemorrhage, diarrhea, diabetes and dysentery. The fruit has antibacterial, antifungal, and antiviral activities ${ }^{12,13,14}$. These two plants have been chosen for the present investigation because of its availability and wider indication in various diseases $15,16,17$. Therefore, in present work a humble attempt was made to detect the presence of antifungal activities of this plant's fruits by a simple and commonly used agar disk diffusion method for investigation and their Phenolic and Flavanoid content as well as their antioxidant activities. 


\section{MATERIALS AND METHODS:}

\subsection{Procurement of Plant material and development of} extract:

The fruit samples of Terminalia chebula and Emblica officinalis was taken from Ayodhya region of Uttar Pradesh in India. The development of plant extract was performed by Soxhlet extraction method $100 \mathrm{mg}$ of dried fruit powder of Terminalia chebula and Emblica officinalis

\subsection{Determination of Total Phenolic and Flavonoids Content}

\subsubsection{Reagents and Chemicals}

Folin-Ciocalteu reagent, gallic acid, and quercetin standards were obtained from Sigma-Aldrich Co. Aluminum chloride hexahydrate, methanol, and sodium carbonate were obtained from Fisher Scientific. Water was purified using a Milli-Q system (Millipore).

\subsubsection{Sample Preparation}

About $10-50 \mathrm{mg}$ of the extract was dissolved in $5 \mathrm{~mL}$ methanol and sonicated for 45 minutes at $40^{\circ} \mathrm{C}$ followed by centrifugation at $1,000 \times \mathrm{g}$ for $10 \mathrm{~min}$. The clear supernatant was collected and stored in an amber bottle for analysis.

\subsubsection{Total Phenolic Content}

The total phenolic of the extracts were determined using the Folin and Ciocalteu reagent, following the method described by Singleton and Rossi with slight modifications. Sample and standard readings were made using a spectrophotometer (Cary 50 Bio UV-Vis Spectrophotometer, Varian) at $765 \mathrm{~nm}$ against the reagent blank. Test sample $(0.2 \mathrm{~mL})$ was mixed with $0.6 \mathrm{~mL}$ of water and $0.2 \mathrm{~mL}$ of Folin-Ciocalteu's phenol reagent (1:1). After $5 \mathrm{~min}, 1 \mathrm{~mL}$ of saturated sodium carbonate solution $(8 \% \mathrm{w} / \mathrm{v}$ in water) was added to the mixture and the volume was made up to $3 \mathrm{~mL}$ with distilled water. The reaction was kept in the dark for $30 \mathrm{~min}$ and after centrifuging the absorbance of blue color from different samples was measured at $765 \mathrm{~nm}$. The phenolic content was calculated as gallic acid equivalents $\mathrm{GAE} / \mathrm{g}$ of dry plant material on the basis of a standard curve of gallic acid (5$500 \mathrm{mg} / \mathrm{l}$ ). All determinations were carried out in triplicate.

\subsubsection{Total Flavonoids Content}

The aluminum chloride colorimetric method was used for the determination of the total flavonoid content of the sample. For total flavonoid determination, quercetin was used to make the standard calibration curve. Stock quercetin solution was prepared by dissolving $5.0 \mathrm{mg}$ quercetin in $1.0 \mathrm{ml}$ methanol, then the standard solutions of quercetin were prepared by serial dilutions using methanol (5$200 \mu \mathrm{g} / \mathrm{ml}$ ). An amount of $0.6 \mathrm{~mL}$ diluted standard quercetin solutions or extracts was separately mixed with $0.6 \mathrm{~mL}$ of $2 \%$ aluminum chloride. After mixing, the solution was incubated for $60 \mathrm{~min}$ at room temperature. The absorbance of the reaction mixtures was measured against blank at $420 \mathrm{~nm}$ wavelength with a Varian UV-Vis spectrophotometer (Systronics UV-VIS Double beam spectrophotometer). The concentration of total flavonoid content in the test samples was calculated from the calibration plot and expressed as mg quercetin equivalent $(\mathrm{QE}) / \mathrm{g}$ of dried plant material. All the determinations were carried out in triplicate.

\subsubsection{Determination of Antioxidant Activity}

\subsubsection{Preparation of Extract}

The extracts were dissolved in dimethyl sulfoxide (DMSO) to make a stock solution of $20 \mathrm{mg} / \mathrm{ml}$. The antioxidant activity of the extracts was measured at a concentration of $500 \mu \mathrm{g} / \mathrm{ml}$ by following two methods.

\subsubsection{2,2-Diphenyl-1-picrylhydrazyl (DPPH) Assay}

The capacity of plant extracts $(500 \mu \mathrm{g} / \mathrm{ml})$ to directly react with and quench free radicals was evaluated as described earlier ${ }^{25}$. A stock solution of DPPH $(200 \mu \mathrm{m})$ was prepared in ethanol. The assay was performed in 96-well plates. The reaction mixture, containing $100 \mu \mathrm{l}$ of DPPH and $100 \mu \mathrm{l}$ of the diluted test sample, was incubated at $37^{\circ} \mathrm{C}$ for $30 \mathrm{~min}$. The absorbance was measured at $515 \mathrm{~nm}$. Gallic acid was used as a positive control. Percent DPPH radical scavenging activity was calculated as follows for

Percentage radical Scavenging Assay =

$$
\left\{1-\frac{(\text { sample }- \text { blank })}{(\text { Control }- \text { blank })}\right\} * 100
$$

Gallic acid showed 95\% radical scavenging activity at $20 \mu \mathrm{M}$.

\section{RESULTS AND DISCUSSION}

\subsection{Total Flavanoid and Phenolic Content}

The calculation of total Flavanoid content was performed by taking quercetin as Standard. The values for unknown variables were calculated as $\mathrm{mg} / \mathrm{ml}$.

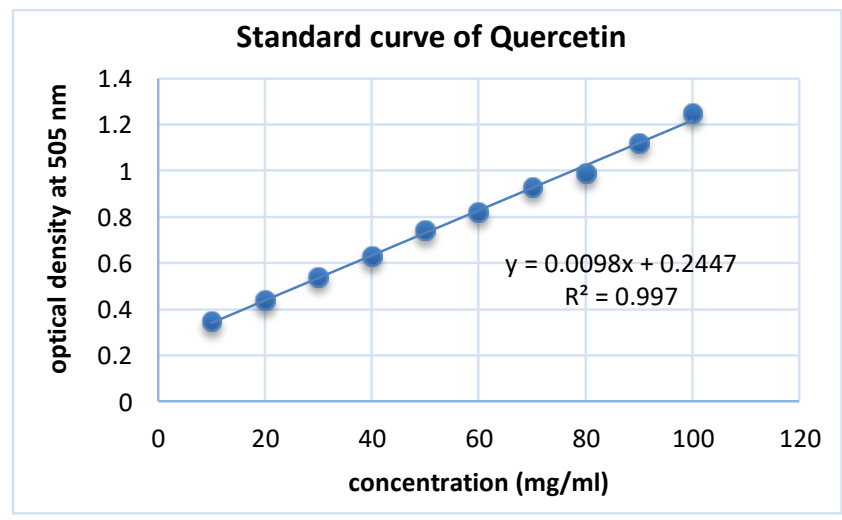

Figure 1: Calibration Plot of Quercetin

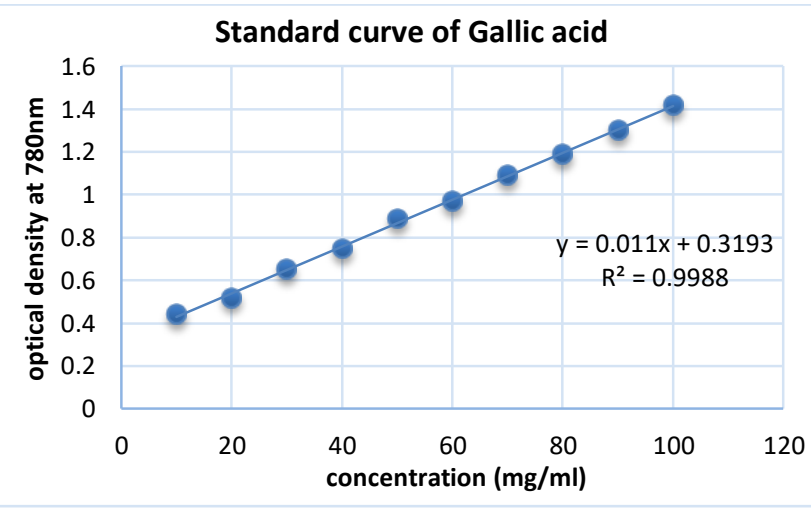

Figure 2: Calibration plot of Gallic acid

The first and foremost experiment of the research investigation to calculate Total Phenolic Content. The phenolic and flavonoid compounds along with the subsequent ascorbic acid contents of the extracts may contribute directly to antioxidative action. The total phenolic content of $70 \%$ methanolic extracts of $T$. chebula, and $E$. officinalis were $43.90 \mathrm{mg} / \mathrm{ml}$ and $39.87 \mathrm{mg} / \mathrm{ml}$. gallic acid equivalent per $100 \mathrm{mg}$ fruit extract, respectively, whereas the flavonoid contents were $43.78 \mathrm{mg} / \mathrm{ml}$ and $39.098 / \mathrm{ml}$ quercetin per $100 \mathrm{mg}$ fruit extract, following the above 
order. This result showed that T. chebula had quite hiked amount of both Flavanoid and Phenolic content by unit values of $3 \mathrm{mg} / \mathrm{ml}$, the comparative increase of Terminalia chebula contents was both in case. Since our work focused to compare the important Phytoconstituents and check whether relatively they have suitable activities with Antioxidants or not. Antioxidant activity for the extracts of $T$. chebula and E. officinalis were calculated using DPPH as reducing radical.

Percentage Radical Scavenging activity of extracts of $T$. chebula and $E$. officinalis

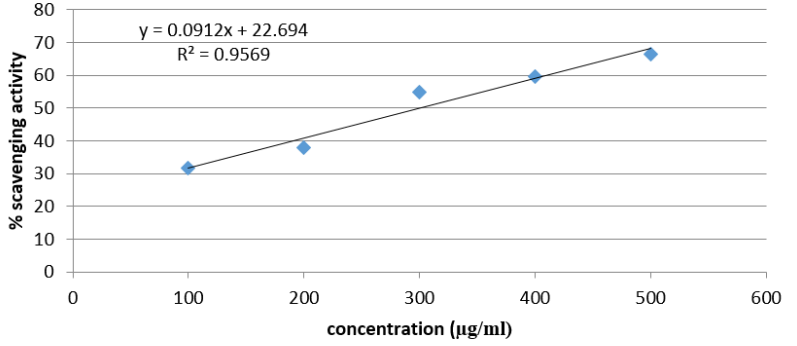

(a)

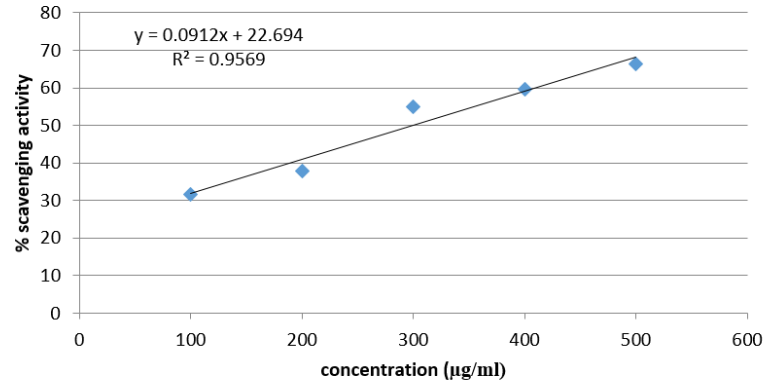

(b)

Figure 3 (a) Percentage radical scavenging assay of $T$. chebula (b) percentage radical scavenging assay of $E$. officinalis Value for $\mathrm{IC}_{50}$ for extract was calculated from the graph placing the value of $\mathrm{y}=50$ and calculating for the value of $\mathrm{x}$.

Table 1: Absorbance and \%inhibition for different concentration of sample extract

\begin{tabular}{|l|l|l|l|l|l|}
\hline S. No & Concentration $(\boldsymbol{\mu g} / \mathbf{m l})$ & $\begin{array}{l}\text { Absorbance } \\
\mathbf{5 1 7 n m})\end{array}$ & $\begin{array}{l}\text { Conc as Ascorbic acid } \\
\text { as equivalent }\end{array}$ & \%Scavenging & Ic 50 \\
\hline 1 & 100 & 0.132 & $76 \mu \mathrm{g} / \mathrm{ml}$ & 31.6062 \\
\hline 2 & 200 & 0.12 & $66.66 \mu \mathrm{g} / \mathrm{ml}$ & 37.8238 \\
\hline 3 & 300 & 0.087 & $39.166 \mu \mathrm{g} / \mathrm{ml}$ & 54.9222 & 290 \\
& 400 & 0.078 & $31.66 \mu \mathrm{g} / \mathrm{ml} / \mathrm{ml}$ \\
\hline 5 & 500 & 0.065 & $20.833 \mu \mathrm{g} / \mathrm{ml}$ & 66.3212 & \\
\end{tabular}

Both of these compounds have good antioxidant potential and their effects on human nutrition and health are considerable. The mechanism of action of flavonoids is through scavenging or chelating process ${ }^{21}$. Phenolic contents are also very important plant constituents because of their scavenging ability due to their hydroxyl groups ${ }^{22}$. Moreover, ascorbic acid acting as a chain breaking antioxidant impairs with the formation of free radicals in the process of formation of intracellular substances throughout the body, including collagen, bone matrix and tooth dentine ${ }^{23}$. From the results, the trend for the ascorbic acid content was found to be E. officinalis $>T$. chebula.

\section{CONCLUSION:}

The investigation found out that radical scavenging assay revealed that fruit extracts possesses individual strong antioxidant activity with different magnitudes of potency in terms Phytoconstituents (Phenols and Flavanoids). Terminalia chebula and Emblica officinalis are common Indian herbs generally gives advantages various diseases as well as body grooming products. The wide use of these fruits in the Indian indigenous system of medicine as antiinflammatory and anti-hepatotoxic may be in part due to their antioxidant potency. Further, the isolation of the compounds responsible for the antioxidant activity has to be taken up which may result in modern drugs from these plants. Also the studies on antioxidant activity of the well- known Ayurvedic formulation, Triphala, a mixture of these fruits, should be carried out. The work is in progress.

\section{REFERENCES:}

1. Braca A, Sortino C, Politi M, Morelli I, Mendez J, Antioxidant activity of flavonoids from Licania licaniaeflora, Journal of Ethnopharmacology, 2002; 79:379-381.

2. Maxwell SR, Prospects for the use of antioxidant therapies, Drugs, 1995; 49:345-361.

3. Niki E, Shimaski $H$, Mino $M$, Antioxidant-free radical and biological defense, 1994; 3-16.

4. Finkel T, Holbrook NJ, Oxidants, oxidative stress and the biology of ageing, Nature, 2000; 408:239-247.

5. Chopra RN, Nayar SL, Chopra IC, Glossary of Indian Medicinal Plants. CSIR, New Delhi, India, 1956; 106:241- 242.

6. Lee HS, Won NH, Kim KH, Lee H, Jun W, Lee KW, Antioxidant effects of aqueous extract of Terminalia chebula in vivo and in vitro, Biology and Pharmaceutical Bulletin, 2005; 28:16391644.

7. Aslokar L, Kakkar KK, Chakre OJ, Supplement to Glossary of Indian Medicinal Plants with Active Principles. Directorate CSIR, New Delhi, India, 1992; 291-293.

8. Rajarama Rao MR, Siddiqui HH, Pharmacological studies on Emblica officinalis, Indian Experimental Biology, 1964; 2:2931.

9. Halliwell B, Gutteridge JMC, Free Radicals in Biology and Medicine, Oxford, England, 1985; 279-315.

10. Roy AK, Dhir H, Talukdar G, Phyllanthus emblica fruit extract and ascorbic acid modify hepatotoxic and renotoxic effects of metals in mice, International Journal of Pharmacology, 1991; 29:117126. 
11. Duarte MCT, Antimicrobial Activity of Medicinal and Aromatic Plants Used in Brazil, MultiCiência, 2006; 7.

12. Mohammed Ali, Text Book of Pharmacognosy, Delhi, India, 1998; 374.

13. Ames BN, Shigenaga MK, and Hagen TM, Oxidants, antioxidants, and the degenerative diseases of aging in the Proceedings of the National Academy of Sciences of the United States of America, 1993; 90(17):7915-7922.

14. Block G, Patterson B, and Subar A, Fruit, vegetables, and cancer prevention: a review of the epidemiological evidence, Nutrition and Cancer, 1992; 18(1):1-29.

15. Vinson JA, Dabbagh JYA, Serry MM, Cai S, Plant polyphenols exhibit lipoprotein-bound antioxidant activity using an in vitro oxidation model for heart disease, Journal of Agricultural and Food Chemistry,1995; 43(11):2798-2799.

16. Paganga G, Miller M, Rice-Evans CA, The polyphenolic content of fruit and vegetables and their antioxidant activities. What does a serving constitute, Free Radical Research, 1999; 30(2):153-162.

17. Kähkönen MP, Hopia AI, Vuorela HJ, Antioxidant activity of plant extracts containing phenolic compounds, Journal of Agricultural and Food Chemistry, 1999; 47(10):3954-3962.
18. Rice-Evans CA, Miller NJ, Bolwell PG, Bramley PM, Pridham JB, The relative antioxidant activities of plant-derived polyphenolic flavonoids, Free Radical Research, 1995; 22 (4):375-383.

19. Sugihar T, Arakawa MO, Furuno K, Anti- and pro-oxidative effects of flavonoids on metal-induced lipid hydroperoxidedependent lipid peroxidation in cultured hepatocytes loaded with $\alpha$-linolenic acid, Free Radical Biology and Medicine,1999; 27(11):1313-1323, 1999.

20. Rice-Evans CA, Miller NJ, and Paganga G, Structure-antioxidant activity relationships of flavonoids and phenolic acids, Free Radical Biology and Medicine, 1996; 20 (7):933-956.

21. Ramarathnam N, Ochi H, Takeuchi M, Antioxidant defense system in vegetable extracts in Natural Antioxidants, Chemistry, Health Effects and Applications, 1997: 76-87.

22. Tapiero H, Tew KD, Ba GN, Mathé G, Polyphenols: do they play a role in the prevention of human pathologies, Biomedicine and Pharmacotherapy, 2002; 56(4):200-207.

23. Sgherri C, Cecconami S, Pinzino C, Navari-Izzo F, and Izzo R, Levels of antioxidants and nutraceuticals in basil grown in hydroponics and soil, Food Chemistry, 2010; 123(2):416-422. 